\title{
Crystal structure of $\mathrm{LaSr}_{3} \mathrm{Fe}_{3} \mathrm{O}_{9}$ and its phase relation with $\mathrm{LaSr}_{3} \mathrm{Fe}_{3} \mathrm{O}_{10}$
}

\author{
Øystein S. Fjellvåg, ${ }^{\dagger}$ Vegar $\emptyset y g a r d e n,{ }^{\dagger}$ Magnus H. Sørby, ${ }^{\star}$ Anja O. Sjåstad,${ }^{\dagger *}$
}

${ }^{\dagger}$ Centre for Materials Science and Nanotechnology, Department of Chemistry, University of Oslo, P.O. Box 1033, N-0315 Oslo, Norway

$\$$ Department for Neutron Materials Characterization, Institute for Energy Technology, P.O. Box 40, NO-2027 Kjeller, Norway

\begin{abstract}
The Ruddlesden-Popper phase $\mathrm{LaSr}_{3} \mathrm{Fe}_{3} \mathrm{O}_{10}$ and its reduced derivatives with nominal composition $\mathrm{LaSr}_{3} \mathrm{Fe}_{3} \mathrm{O}_{10-x}$, with $0<x<1.21$, are described in detail with respect to structure, magnetic order, thermal stability and likely vacancy mechanisms. The structure of the novel $\mathrm{LaSr}_{3} \mathrm{Fe}_{3} \mathrm{O}_{9}(x=1)$ phase is described. The $\mathrm{LaSr}_{3} \mathrm{Fe}_{3} \mathrm{O}_{10-\delta}$ phase prevails for $x<0.51$, whereas $\mathrm{LaSr}_{3} \mathrm{Fe}_{3} \mathrm{O}_{9 \pm \varepsilon}$ prevails for $x>0.85$. The phases are separated by a two-phase region $0.51<x<$ 0.85. By combined Rietveld refinements of high-resolution powder synchrotron and neutron diffraction, the crystallographic and magnetic structure of $\mathrm{LaSr}_{3} \mathrm{Fe}_{3} \mathrm{O}_{9}$ is described. $\mathrm{LaSr}_{3} \mathrm{Fe}_{3} \mathrm{O}_{9}$ takes a layer like RP3 type structure with features of the brownmillerite structure in the triple perovskite type slabs; unit cell dimensions $a=28.7562(13) \AA, b=5.5280(2) \AA, c=5.4583(2)$ $\AA$, space group $\mathrm{Cmcm}$. $\mathrm{LaSr}_{3} \mathrm{Fe}_{3} \mathrm{O}_{9}$ is an antiferromagnet with $\mathrm{T}_{\mathrm{N}}>350 \mathrm{~K}$ and with a G-type magnetic structure, magnetic space group $P_{C} b c m$. Based on unit cell volume considerations, local oxygen vacancy ordering schemes are suggested.
\end{abstract}




\section{Introduction}

Multicomponent transition metal oxides display a wide range of functional properties with potential for applications based on ionic conductivity, magnetic, electrical or optical properties. There is a continuous race for improved and new materials with higher yields, enhanced stability, lower costs, etc. In this respect the perovskite family is of particular interest. Its members display functional properties such as high $T_{C}$ superconductivity,[1] ferroic properties,[2] catalytic selectivity,[3] colossal magnetoresistance[4] and ionic conductivity.[5] The closely related Ruddlesden-Popper $\left(\mathrm{A}_{n+1} \mathrm{~B}_{n} \mathrm{O}_{3 n+1}, \mathrm{RP} n\right)$ type structure is built up of $n$ perovskite slabs separated by half a rock salt layer. The layer-like RP compounds exhibits similar physical properties. Moreover, the reduced dimensionality of the 2D-like RP phases may give rise to additional phenomena.

$\mathrm{LaSr}_{3} \mathrm{Fe}_{3} \mathrm{O}_{10}$ takes the RP3 type structure and crystallizes in space group $14 / \mathrm{mmm}$.[6] Despite knowing the compound displays oxygen non-stoichiometry, a complete picture of the defect situation is not at hand. Based on neutron diffraction, Lee et al. found that vacancies in $\mathrm{LaSr}_{3} \mathrm{Fe}_{3} \mathrm{O}_{10-x}$ form in the middle perovskite slab in the RP3 type structure.[6] This is supported by computer simulations by Tsipis et al. who found that tetrahedral iron in the middle perovskite layer is formed when oxygen is removed from $\mathrm{LaSr}_{3} \mathrm{Fe}_{3} \mathrm{O}_{10}$.[7] Tsipis et al. further suggested that the more strongly reduced $\mathrm{LaSr}_{3} \mathrm{Fe}_{2.7} \mathrm{Al}_{0.3} \mathrm{O}_{9}$ compound takes a similar structure to that of orthorhombic $\mathrm{NdSr}_{3} \mathrm{Fe}_{3} \mathrm{O}_{9}$.[7] $\mathrm{NdSr}_{3} \mathrm{Fe}_{3} \mathrm{O}_{9}$ is an oxygen deficient derivative of the $\mathrm{RP} 3$ $\mathrm{NdSr}_{3} \mathrm{Fe}_{3} \mathrm{O}_{10}$ and is described as a RP3 compound where the octahedra in the middle perovskite layer are exchanged with tetrahedral, similar to the brownmillerite structure.[8,9] The structural arrangement is thus also similar to the non-stoichiometric perovskite $\mathrm{LaSr}_{2} \mathrm{Fe}_{3} \mathrm{O}_{8+y}$, different only in the introduction of an intergrowth layer between the perovskite layers, which is the signature of RP-type structures.[10, 11] This is emphasized by the similar Néel temperature of $\mathrm{NdSr}_{3} \mathrm{Fe}_{3} \mathrm{O}_{9}$ and $\mathrm{LaSr}_{2} \mathrm{Fe}_{3} \mathrm{O}_{8+y}$ of 600 and $715 \pm 5 \mathrm{~K}$, respectively.[8, 10]

$\mathrm{LaSr}_{3} \mathrm{Fe}_{3} \mathrm{O}_{10}$ transforms into $\mathrm{LaSr}_{3} \mathrm{Fe}_{3} \mathrm{O}_{9}$ upon reduction.[12] Although the structure is not reported in detail, $\mathrm{LaSr}_{3} \mathrm{Fe}_{3} \mathrm{O}_{9}$ is indexed in the orthorhombic space group Bbmm.[12] The compound shows the unusual property of being able to intercalate water and thereby form an hydrated hydroxide-derivative $\mathrm{LaSr}_{3} \mathrm{Fe}_{3} \mathrm{O}_{8}(\mathrm{OH})_{2} \cdot x \mathrm{H}_{2} \mathrm{O}$.[12] The latter material, $\mathrm{LaSr}_{3} \mathrm{Fe}_{3} \mathrm{O}_{8}(\mathrm{OH})_{2} \cdot x \mathrm{H}_{2} \mathrm{O}$, has attracted attention due to its potential as electrode material for metal-air batteries because of its high ionic conductivity.[13] 
The current work reports on $\mathrm{LaSr}_{3} \mathrm{Fe}_{3} \mathrm{O}_{10-x}(0<x<1.2)$, as obtained by post-reduction of $\mathrm{LaSr}_{3} \mathrm{Fe}_{3} \mathrm{O}_{10}$. We describe the crystal structure and the oxygen vacancy ordering of $\mathrm{LaSr}_{3} \mathrm{Fe}_{3} \mathrm{O}_{9}$ with basis in combined Rietveld refinements of high-resolution powder synchrotron X-ray diffraction (SR-XRD) and powder neutron diffraction (ND). The magnetic properties of $\mathrm{LaSr}_{3} \mathrm{Fe}_{3} \mathrm{O}_{9}$ are characterized by means of magnetization (PPMS) studies, whereas the magnetic structure is determined on basis of ND analysis. The stoichiometry and phase-relations between $\mathrm{LaSr}_{3} \mathrm{Fe}_{3} \mathrm{O}_{10-\delta}$ and $\mathrm{LaSr}_{3} \mathrm{Fe}_{3} \mathrm{O}_{9 \pm \varepsilon}$, including their reversible transformation and defect situation, were explored by combination of cerimetric titration, thermogravimetry (TGA), XRD, in situ SR-XRD and volume considerations.

\section{Experimental}

\section{Synthesis of oxygen stoichiometric $\mathrm{LaSr}_{3} \mathrm{Fe}_{3} \mathrm{O}_{10}$}

$\mathrm{LaSr}_{3} \mathrm{Fe}_{3} \mathrm{O}_{10}$ was synthesized by the citric acid method starting from $0.1 \mathrm{M}$ lanthanum-, strontium- and iron(III) nitrate solutions (reactants from Sigma-Aldrich, > $99.9 \%$ ). Accurate metal content of the nitrate solutions was determined by thermogravimetry. Stoichiometric quantities of the cationic solutions were mixed with excess molten citric acid monohydrate (Sigma-Aldrich, 99.5\%) under vigorous stirring. Water and nitrous gasses were evaporated from the solution, thereby forming a gel that was dried overnight at $553 \mathrm{~K}$ and calcined at 723 $\mathrm{K}$ for $12 \mathrm{~h}$. The obtained black powder was crushed and heat-treated at $1173 \mathrm{~K}$ for $12 \mathrm{~h}$, before regrinding and a last annealing at $1573 \mathrm{~K}$ for $12 \mathrm{~h}$. Finally, the sample was cooled at a rate of $2.5 \mathrm{~K} \mathrm{~min}^{-1}$ to room temperature, giving an oxygen stoichiometry of $\mathrm{LaSr}_{3} \mathrm{Fe}_{3} \mathrm{O}_{9.97}$ (cerimetric titration, see details below). All heat treatments were performed in air.

\section{Preparation of oxygen defective $\mathrm{LaSr}_{3} \mathrm{Fe}_{3} \mathrm{O}_{10-x}$}

$\mathrm{LaSr}_{3} \mathrm{Fe}_{3} \mathrm{O}_{10-x}$ samples with controlled oxygen content were obtained by reducing $\mathrm{LaSr}_{3} \mathrm{Fe}_{3} \mathrm{O}_{9.97}$ with $\mathrm{NbO}$ (99 \%, Alpha Aesar) according to the reaction:

$$
\mathrm{LaSr}_{3} \mathrm{Fe}_{3} \mathrm{O}_{10}+x \cdot \frac{2}{3} \mathrm{NbO} \rightarrow \mathrm{LaSr}_{3} \mathrm{Fe}_{3} \mathrm{O}_{10-x}+x \cdot \frac{1}{3} \mathrm{Nb}_{2} \mathrm{O}_{5}
$$

We obtain the reduced complex oxide by loading two alumina crucibles with stoichiometric amounts of $\mathrm{LaSr}_{3} \mathrm{Fe}_{3} \mathrm{O}_{10}$ and $\mathrm{NbO}$, and sealing them in a quartz ampule under vacuum before heating to $1173 \mathrm{~K}$ for $12 \mathrm{~h}$. To avoid potential re-oxidation, hydration or undesired carbon 
dioxide uptake, all handling of the ampules were done in an argon filled glovebox from MBraun.[12]

Exact oxygen content was determined by cerimetric titration. Mohr salt, $\left(\mathrm{NH}_{4}\right)_{2} \mathrm{Fe}\left(\mathrm{SO}_{4}\right)_{2} \cdot 6 \mathrm{H}_{2} \mathrm{O}$ (99\%, Sigma Aldrich), and a small amount of the sample was dissolved in $1 \mathrm{M} \mathrm{HCl}$. Three parallels were prepared and titrated with $0.1 \mathrm{M} \mathrm{Ce}\left(\mathrm{SO}_{4}\right)_{2}$ (volumetric, Fluka). The titration was done in inert $\operatorname{Ar}(5 \mathrm{~N}$, Aga). Exact formula weight of the Mohr salt was determined gravimetrically (four parallels). The exact concentration of the $\mathrm{Ce}\left(\mathrm{SO}_{4}\right)_{2}$ solution was determined separately by titrations with Mohr salt.

\section{Crystal structure analysis}

High-resolution SR-XRD was collected for $\mathrm{LaSr}_{3} \mathrm{Fe}_{3} \mathrm{O}_{9}$ at the Swiss-Norwegian beamline (SNBL, BM01B) at the European Synchrotron Radiation Facility (ESRF, Grenoble, France) for the scattering angle range $1-40.5^{\circ}$ in steps of $\Delta(2 \theta)=0.005^{\circ}$. Monochromatic X-rays were obtained from a channel-cut $\mathrm{Si}(111)$ crystal, and $\mathrm{LaB}_{6}$ was used for wavelength $(\lambda=0.50513$ $\AA$ ) and detector calibration. ND data were collected using the two-axis powder diffractometer PUS at the JEEP II reactor at Institute for Energy Technology (IFE), Kjeller, Norway, with $\lambda=$ 1.5539 Å.[14] The sample was measured in a cylindrical vanadium sample container sealed with an indium wire. Diffraction patterns were collected at 8 and $298 \mathrm{~K}$, the low-temperature data were obtained in a Displex type cryostat. Data were collected by two detector units, each containing a vertical stack of seven position sensitive ${ }^{3} \mathrm{He}$ detectors each covering $20^{\circ}$ in $2 \theta$. The $2 \theta$-range $10-130^{\circ}$ was covered by measuring each bank in three different positions. The obtained data were binned in steps of $\Delta(2 \theta)=0.05^{\circ}$.

The $\mathrm{LaSr}_{3} \mathrm{Fe}_{3} \mathrm{O}_{9}$ crystal structure was simultaneous refined using the high resolution SR-XRD and ND datasets in TOPAS V5.[15, 16] In the combined Rietveld refinement, the parameters restricted to be identical for both datasets are listed in Table S1. The datasets were weighted according to the standard routines in TOPAS V5. For the ND data, a purely nuclear structure and a magnetic structure with just magnetic contribution were refined. Chebyshev polynomials were used for background. The peak shape of the SR-XRD and ND patterns were modeled with full-Voigt and Thompson-Cox-Hastings pseudo-Voigt peak shapes, respectively. The thermal displacement parameters were constrained to be equal for sites with the same elements. The relative occupancy of lanthanum and strontium was refined with the overall sum locked to one. 
The magnetic structure and space group was identified by ISODISTORT.[17] Due to the symmetry of the magnetic space group, only $\mathrm{M}_{\mathrm{z}}$ was refined for the two iron sites.

Isothermal and variable temperature diffraction data of $\mathrm{LaSr}_{3} \mathrm{Fe}_{3} \mathrm{O}_{9.22}$ were collected at SNBL (BM01A; wavelength $0.69687 \AA$ ) using a Pilatus2M detector and a counting time of $10 \mathrm{~s}(+10$ s read out/wait). $\mathrm{LaSr}_{3} \mathrm{Fe}_{3} \mathrm{O}_{9.22}$ was packed and sealed in a $0.3 \mathrm{~mm}$ quartz capillary inside an Ar-filled glovebox. The capillary was heated to $663 \mathrm{~K}$, then the tip of the capillary was cut, and the progressing oxidation was monitored by diffraction. The $2 \mathrm{D}$ images were integrated using the Fit2D program and rebinned into $1 \mathrm{D}$ datasets for the range $1.8-49^{\circ}$ in steps of $\Delta(2 \theta)=$ $0.015^{\circ} . \mathrm{LaB}_{6}$ was used for wavelength and detector calibration. The diffraction patterns (175 in total) were analyzed by surface Rietveld refinements in TOPAS V5.[15, 16] In the surface Rietveld refinement, sample displacement and peak shape was refined as global parameters, while lattice parameters, scale factor and background were refined for the individual diffraction patterns. Atomic positions were not refined, but acquired from the structural determination of $\mathrm{LaSr}_{3} \mathrm{Fe}_{3} \mathrm{O}_{9}$ and from the literature for $\mathrm{LaSr}_{3} \mathrm{Fe}_{3} \mathrm{O}_{10}$.[6]

XRD of the reduced phases, $\mathrm{LaSr}_{3} \mathrm{Fe}_{3} \mathrm{O}_{10-}$, were collected in transmission capillary geometry with a Bruker D8-A25 with Ge(111) Johansson monochromator, Lynxeye detector and $\mathrm{Cu} \mathrm{K}_{\alpha 1}$ radiation at the RECX laboratory, University of Oslo. The samples were packed and sealed in $0.5 \mathrm{~mm}$ capillaries inside an Ar filled glove box. Diffraction data were collected for $2 \theta=3$ $90^{\circ}$, with a step size of $0.011^{\circ}$. Profile refinements were carried out in TOPAS V5 for accurate determination of unit cell parameters. $[15,16]$ Three samples with composition in a two-phase region were simultaneously refined with two set of unit cell parameters, one set for each phase. The limits of the two-phase region were calculated based on refined phase fractions.

\section{Thermal and physical characterization}

Thermogravimetry (TG) and Differential Scanning Calorimetry (DSC) data were obtained from 298 to $1473 \mathrm{~K}$ of approximately $20 \mathrm{mg}$ samples using a combined TGA/DSC Netzsch STA 449 F1 Jupiter instrument, at a heating rate of $1 \mathrm{~K} \mathrm{~min}^{-1}$ in $\mathrm{N}_{2}(5 \mathrm{~N}, \mathrm{AGA})$ or $\mathrm{O}_{2}(5 \mathrm{~N}$, Praxair) gas flow. $\mathrm{N}_{2}$ (5 N, Praxair) was used as protective gas for experiments in $\mathrm{O}_{2}$. The sample was kept in a platinum crucible. The buoyancy effect was corrected for by subtracting a blank reference scan obtained at the same experimental conditions. 
Magnetization measurements were performed using a Quantum Design PPMS in the temperature range $4-350 \mathrm{~K}$ and an applied field of $10 \mathrm{kOe}$. Magnetization data measured at lower fields gave poor data due to the antiferromagnetic nature of the material. The $\mathrm{LaSr}_{3} \mathrm{Fe}_{3} \mathrm{O}_{9}$ sample $(76.7 \mathrm{mg}$ ) was contained in an evacuated high purity quartz ampoule and measured under Zero Field (ZFC) and Field Cooled (FC) conditions.

\section{Results and discussion}

According to XRD and analysis by cerimetric titration, the as-synthesized $\mathrm{LaSr}_{3} \mathrm{Fe}_{3} \mathrm{O}_{10}$ is phase pure with an oxygen stoichiometry of $\mathrm{LaSr}_{3} \mathrm{Fe}_{3} \mathrm{O}_{9.97}$. The compound takes a tetragonal $(I 4 / \mathrm{mmm}) \mathrm{RP} 3$ type structure (Figure 1a) with lattice parameters $a=3.8671(3) \AA$ and $c=$ 28.018(2) $\AA$, in accordance with Lee et al. [6] With basis in $\mathrm{LaSr}_{3} \mathrm{Fe}_{3} \mathrm{O}_{9.97}$, we prepared a series of oxygen deficient samples $\left(\mathrm{LaSr}_{3} \mathrm{Fe}_{3} \mathrm{O}_{10-x}\right)$ with well-defined (nominal) oxygen contents. Careful analysis of the samples showed that they contained either one or two phases; one of the two single phases $\mathrm{LaSr}_{3} \mathrm{Fe}_{3} \mathrm{O}_{10}\left(\mathrm{LaSr}_{3} \mathrm{Fe}_{3} \mathrm{O}_{10-\delta}\right)$ and $\mathrm{LaSr}_{3} \mathrm{Fe}_{3} \mathrm{O}_{9}\left(\mathrm{LaSr}_{3} \mathrm{Fe}_{3} \mathrm{O}_{9 \pm \varepsilon}\right)$, or a mixture of these two. In the following, we present crystal structural analysis of $\mathrm{LaSr}_{3} \mathrm{Fe}_{3} \mathrm{O}_{9}$ including description of its magnetic properties, and furthermore a phase analysis of $\mathrm{LaSr}_{3} \mathrm{Fe}_{3} \mathrm{O}_{10-x}$ in the oxygen stoichiometry range $0<x<1.21$.

\section{Crystal structure, magnetic structure and magnetic properties of $\mathrm{LaSr}_{3} \mathrm{Fe}_{3} \mathrm{O}_{9}$}

A full description of the crystal structure of $\mathrm{LaSr}_{3} \mathrm{Fe}_{3} \mathrm{O}_{9}$ is lacking. However, Øygarden et al. indexed its XRD pattern in the orthorhombic space group Bbmm,[12] and Barrier et al. reported a structural analysis of the related compound $\mathrm{NdSr}_{3} \mathrm{Fe}_{3} \mathrm{O}_{9}$ in its paramagnetic state at $673 \mathrm{~K}$.[8] The structural analysis of $\mathrm{LaSr}_{3} \mathrm{Fe}_{3} \mathrm{O}_{9}$ was initiated with the available information, first by converting the reported space group Bbmm (Bbmm: $a=5.5479 \AA$, $b=5.4846 \AA$, and $c=28.8846$ $\AA$ ) to standard settings, i.e. $C m c m$ (Cmcm: $a=28.8846 \AA, b=5.5479 \AA$, and $c=5.4846 \AA$ ). For achieving a precise structural description, we performed combined refinements of SR-XRD and ND data (Figure 2 and Figure S1). The additional peaks from antiferromagnetic ordering in the ND patterns ( 8 and $298 \mathrm{~K}$ ) that were not in accordance with the crystallographic space group, Figure 2 and Figure S1, were assigned by ISODISTORT to the magnetic space group $P_{C} b c m$ (BNS 57.391) with a cell shifted $(1 / 4,1 / 4,0)$ and a propagation vector $k=0$.[17] The magnetic structure was successfully refined together with the crystallographic structure, providing good fit to the peaks with magnetic origin, Figure 2 and Figure S1. Illustrations of the crystal- and magnetic structures are presented in Figure $1 \mathrm{~b}$ and c. Crystallographic data 
obtained at 8 and $298 \mathrm{~K}$ are summarized in Table 1, Table 2 and Table S2. The magnetic moments extracted from the refined magnetic structure are given in Table 3.
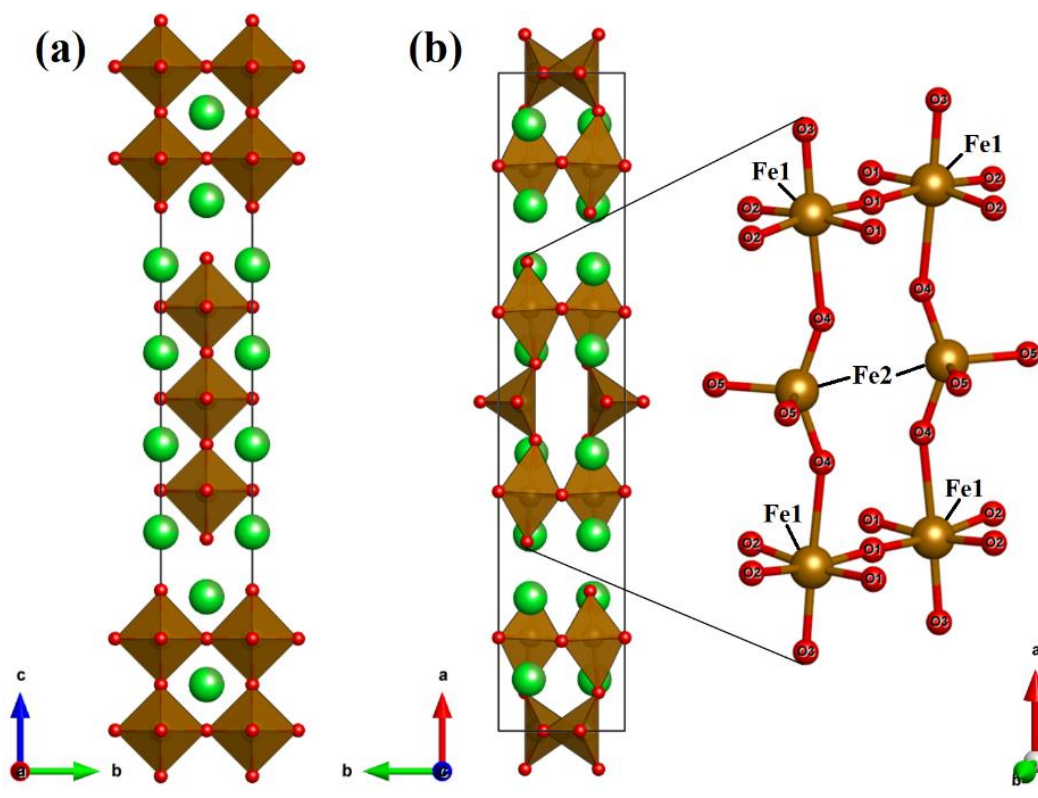

(c)
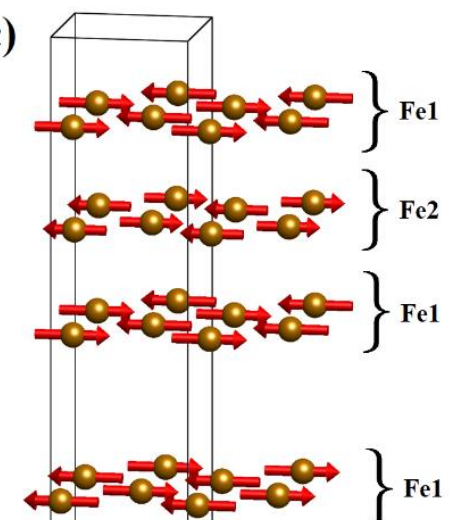

Figure 1: Crystal structure of (a) $\mathrm{LaSr}_{3} \mathrm{Fe}_{3} \mathrm{O}_{10}($ (I4/mmm) viewed along the $a$-axis and (b) $\mathrm{LaSr}_{3} \mathrm{Fe}_{3} \mathrm{O}_{9}(\mathrm{Cmcm})$ viewed along the $c$-axis. In the crystal structure, the octahedra of the middle perovskite layer of the RP3 is now replaced by tetrahedra. Light green, dark green, orange and red spheres correspond to strontium, lanthanum, iron and oxygen atoms. (c): Visualization of the G-type antiferromagnetic structure of $\mathrm{LaSr}_{3} \mathrm{Fe}_{3} \mathrm{O}_{9}$ at $8 \mathrm{~K}$ described in magnetic space group $P_{c} b c m$. The origin of the magnetic cell is shifted $(1 / 4,1 / 4,0)$ relative to the crystallographic cell. Only the iron atoms are displayed. The magnetic moments of the tetrahedral iron atoms (Fe2) are slightly lower than those of the octahedral iron atoms (Fe1), see Table 3. 


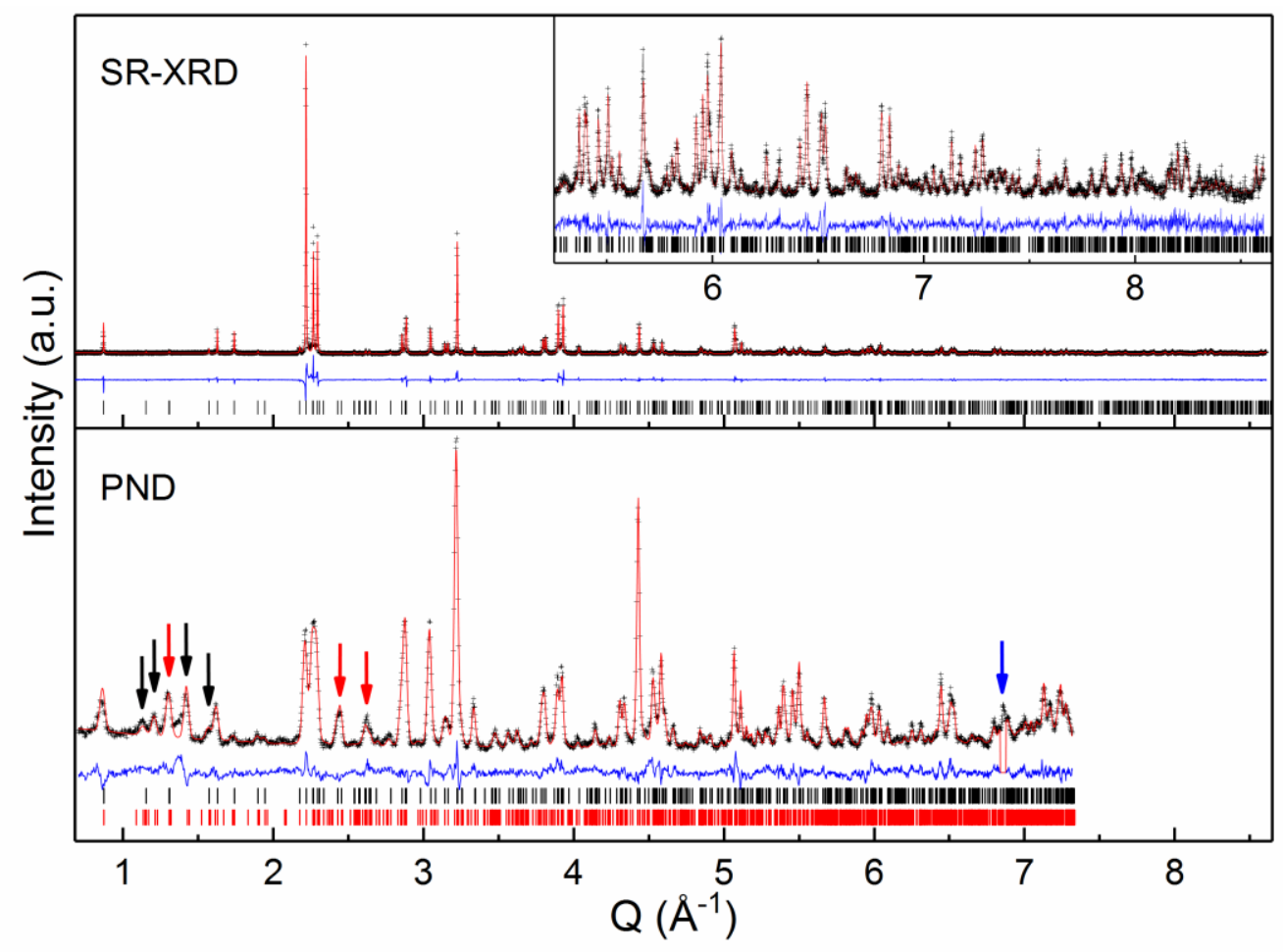

Figure 2: Observed (black), calculated (red) and difference (blue) intensity profile from combined Rietveld refinements of high resolution SR-XRD (top) and ND (bottom) patterns of $\mathrm{LaSr}_{3} \mathrm{Fe}_{3} \mathrm{O}_{9}$ at $298 \mathrm{~K}$. The positions of Bragg reflections allowed by the crystallographic $(\mathrm{Cmcm})$ and magnetic $\left(P_{C} b c m\right)$ space group are marked with black and red bars, respectively. Black arrows indicate reflections with only magnetic contribution and red arrows indicate reflections with both nuclear and magnetic contribution. The reflection in the ND pattern at $6.9 \AA^{-1}$ is from the cryostat (blue arrow).

The structure analysis confirms $\mathrm{LaSr}_{3} \mathrm{Fe}_{3} \mathrm{O}_{9}$ to be isostructural to $\mathrm{NdSr}_{3} \mathrm{Fe}_{3} \mathrm{O}_{9}$ and represents hence an ordered oxygen-deficient RP3 phase. The RP3 structure consists of slabs of three perovskite layers separated by a half rock salt layer (Figure 1a). While in $\mathrm{LaSr}_{3} \mathrm{Fe}_{3} \mathrm{O}_{9}$, the octahedra in the middle layer of the perovskite slab is exchanged with tetrahedra (Figure $1 \mathrm{~b}$ and Figure S2), making the slab similar to the brownmillerite- and the $\mathrm{LaSr}_{2} \mathrm{Fe}_{3} \mathrm{O}_{8+y}$ framework.[811] Hence, the crystal structure of $\mathrm{LaSr}_{3} \mathrm{Fe}_{3} \mathrm{O}_{9}$ can be describes as composed of brownmillerite slabs separated by a half rock salt layer.

By comparing the crystal structures of $\mathrm{LaSr}_{3} \mathrm{Fe}_{3} \mathrm{O}_{10}$ and $\mathrm{LaSr}_{3} \mathrm{Fe}_{3} \mathrm{O}_{9}$, it becomes evident that converting the three-layered perovskite slab to a brownmillerite slab leads to an elongation of the slab by $\sim 0.25 \AA$ in the stacking direction. Similar to the brownmillerite and $\mathrm{LaSr}_{2} \mathrm{Fe}_{3} \mathrm{O}_{8+y}$ framework, elongation and corresponding volume increase is caused by the expansion of the 
Fe-O bond in the octahedra directed towards the tetrahedral layer.[8-11] According to the bond valence concept (using the parameters $\mathrm{B}=0.37$ and $\mathrm{R}_{0}=1.759$ ), [18] the $\mathrm{Fe}-\mathrm{O}$ separations in $\mathrm{LaSr}_{3} \mathrm{Fe}_{3} \mathrm{O}_{9}$ correspond to iron valences of 3.07 (Fe1) and 2.85 (Fe2) for the octahedra and the tetrahedra, respectively. This is in good agreement with the expected Fe(III) state based on stoichiometry and the rusty red color of the compound. For $\mathrm{LaSr}_{3} \mathrm{Fe}_{3} \mathrm{O}_{10}$, the corresponding bond valence sums are 3.41 and 3.72 for the upper/lower and middle octahedra in the RP3 slab, quite close to the average oxidation state of iron in $\mathrm{LaSr}_{3} \mathrm{Fe}_{3} \mathrm{O}_{10}$ of 3.67.

The magnetic structure of $\mathrm{LaSr}_{3} \mathrm{Fe}_{3} \mathrm{O}_{9}$ is unraveled from analysis of ND data in tandem with magnetic susceptibility measurements. Neutron diffraction clearly proves that $\mathrm{LaSr}_{3} \mathrm{Fe}_{3} \mathrm{O}_{9}$ is magnetically ordered at 8 and $298 \mathrm{~K}$ and can be described in the magnetic space group $P_{C} b c m$. The analysis shows that $\mathrm{LaSr}_{3} \mathrm{Fe}_{3} \mathrm{O}_{9}$ is a G-type antiferromagnet, Figure 1c, with a similar spin configuration as $\mathrm{LaSr}_{2} \mathrm{Fe}_{3} \mathrm{O}_{8+y}$.[11] The magnetic moments order antiferromagnetically within the brownmillerite slabs and across the rock salt layer. Thus, the two brownmillerite slabs pictured in Figure 1c have opposite magnetic spin directions. The magnetic moments of 3.99(5) and 3.58(8) $\mu_{\mathrm{B}}$ at $8 \mathrm{~K}$ on the octahedral iron ( $\left.\mathrm{Fe} 1\right)$ and the tetrahedral iron site ( $\left.\mathrm{Fe} 2\right)$ respectively; the magnetic moments are given in Table 3. The lower magnetic moment on the tetrahedral site is consistent with $\mathrm{LaSr}_{2} \mathrm{Fe}_{3} \mathrm{O}_{8+y}$, as reported by Battle et al.[11] They attributed this to structural disorder on the tetrahedral site lowering the super-exchange interactions, which in turn may be the case for $\mathrm{LaSr}_{3} \mathrm{Fe}_{3} \mathrm{O}_{9}$ as well.

Table 1: Unit cell data and reliability factors for the combined SR-XRD and ND Rietveld refinements of orthorhombic $\mathrm{LaSr}_{3} \mathrm{Fe}_{3} \mathrm{O}_{9}$, space group $\mathrm{Cmcm}$. Calculated standard deviations in parentheses.

$\begin{array}{llll} & & 8 \mathrm{~K} & 298 \mathrm{~K} \\ a(\AA) & & 28.7559(13) & 28.8739(4) \\ b(\AA) & & 5.5279(2) & 5.54507(7) \\ c(\AA) & 5.4582(2) & 5.47804(6) \\ V\left(\AA^{3}\right) & & 867.64(6) & 877.076(19) \\ Z & & 4 & 4 \\ R_{p} & & & 13.977 \\ & \text { SR-XRD } & 6.768 & 6.676 \\ R_{w p} & \text { ND } & & 18.196 \\ & \text { SR-XRD } & 8.745 & 8.638 \\ R_{\exp } & \text { ND } & & 10.035 \\ & \text { SR-XRD } & & 5.454\end{array}$


Table 2: Crystal structure data for $\mathrm{LaSr}_{3} \mathrm{Fe}_{3} \mathrm{O}_{9}$ as obtained from combined Rietveld refinement of SR-XRD and ND data (space group Cmcm; $8 \mathrm{~K}$ ) giving lattice parameters of $a=28.7559(13) \AA$, $b=\mathbf{5 . 5 2 8 0}(2) \AA, c=\mathbf{5 . 4 5 8 3}(2) \AA$. Calculated standard deviations are given in parentheses.

$\begin{array}{ccccccc}\text { Atom } & \text { Wyckoff } & \mathrm{x} & \mathrm{y} & \mathrm{z} & \text { Occupancy } & \mathrm{U}_{\text {iso }} \\ \mathrm{La} 1 & 8 \mathrm{~g} & 0.20181(6) & 0.2520(4) & 0.25 & 0.2157(10) & 0.0058(6) \\ \mathrm{Sr} 1 & 8 \mathrm{~g} & 0.20181(6) & 0.2520(4) & 0.25 & 0.7843(10) & 0.0058(6) \\ \mathrm{La} 2 & 8 \mathrm{~g} & 0.07850(7) & 0.2399(4) & 0.25 & 0.2843(10) & 0.0058(6) \\ \mathrm{Sr} 2 & 8 \mathrm{~g} & 0.07850(7) & 0.2399(4) & 0.25 & 0.7157(10) & 0.0058(6) \\ \mathrm{Fe} 1 & 8 \mathrm{~g} & 0.64349(10) & 0.2483(7) & 0.25 & 1 & 0.0096(4) \\ \mathrm{Fe} 2 & 4 \mathrm{c} & 0 & 0.6892(7) & 0.25 & 1 & 0.0096(4) \\ \mathrm{O} 1 & 8 \mathrm{e} & 0.8587(3) & 0 & 0 & 1 & 0.0077(8) \\ \text { O2 } & 8 \mathrm{e} & 0.6360(2) & 0 & 0 & 1 & 0.0077(8) \\ \mathrm{O} 3 & 8 \mathrm{~g} & 0.71285(17) & 0.2248(12) & 0.25 & 1 & 0.0077(8) \\ \text { O4 } & 8 \mathrm{~g} & 0.55865(18) & 0.2939(12) & 0.25 & 1 & 0.0077(8) \\ \text { O5 } & 8 \mathrm{f} & 0 & 0.358(2) & 0.359(2) & 0.5 & 0.0077(8)\end{array}$

Table 3: Magnetic moments of iron atoms from Rietveld refinements of ND. The symmetry of the magnetic space group, $P_{c} b c m$, allows only refinement of $M_{z}$, hence $M_{x}$ and $M_{y}$ is zero by symmetry. Calculated standard deviations are given in parentheses.

$\begin{array}{lll} & \mathrm{M}_{\mathrm{z}} \mathrm{Fe} 1\left(\mu_{\mathrm{B}}\right) & \mathrm{M}_{\mathrm{z}} \mathrm{Fe} 2\left(\mu_{\mathrm{B}}\right) \\ 8 \mathrm{~K} & 3.99(5) & 3.58(8) \\ 298 \mathrm{~K} & 3.24(8) & 2.7(1)\end{array}$

The temperature dependence of the magnetic susceptibility (Figure 3a) supports the antiferromagnetic nature of $\mathrm{LaSr}_{3} \mathrm{Fe}_{3} \mathrm{O}_{9}$ with a transition to the paramagnetic state above the maximum temperature achievable in the PPMS $(350 \mathrm{~K})$, possibly similarly to that of $\mathrm{NdSr}_{3} \mathrm{FeO}_{9}$ and $\mathrm{LaSr}_{2} \mathrm{Fe}_{3} \mathrm{O}_{8+y}$ which is antiferromagnetic up to 600 and $715 \pm 5 \mathrm{~K}$, respectively.[8, 10] Notably, field dependent $\mathrm{M}(H)$ measurements at $4 \mathrm{~K}$ reveal a small hysteresis (Figure $3 \mathrm{~b}$ ) and a weakly S-shaped $\mathrm{M}(H)$ behavior. Currently, we cannot explain this contribution, but it has most likely its origin in a minor impurity (not detected by XRD) obtained during sample preparation. Number of unpaired electrons at high field $(\mathrm{H}>80 \mathrm{kOe})$ is calculated to be 0.14 at $4 \mathrm{~K}$. This low value confirms the strong antiferromagnetic coupling in the material. 


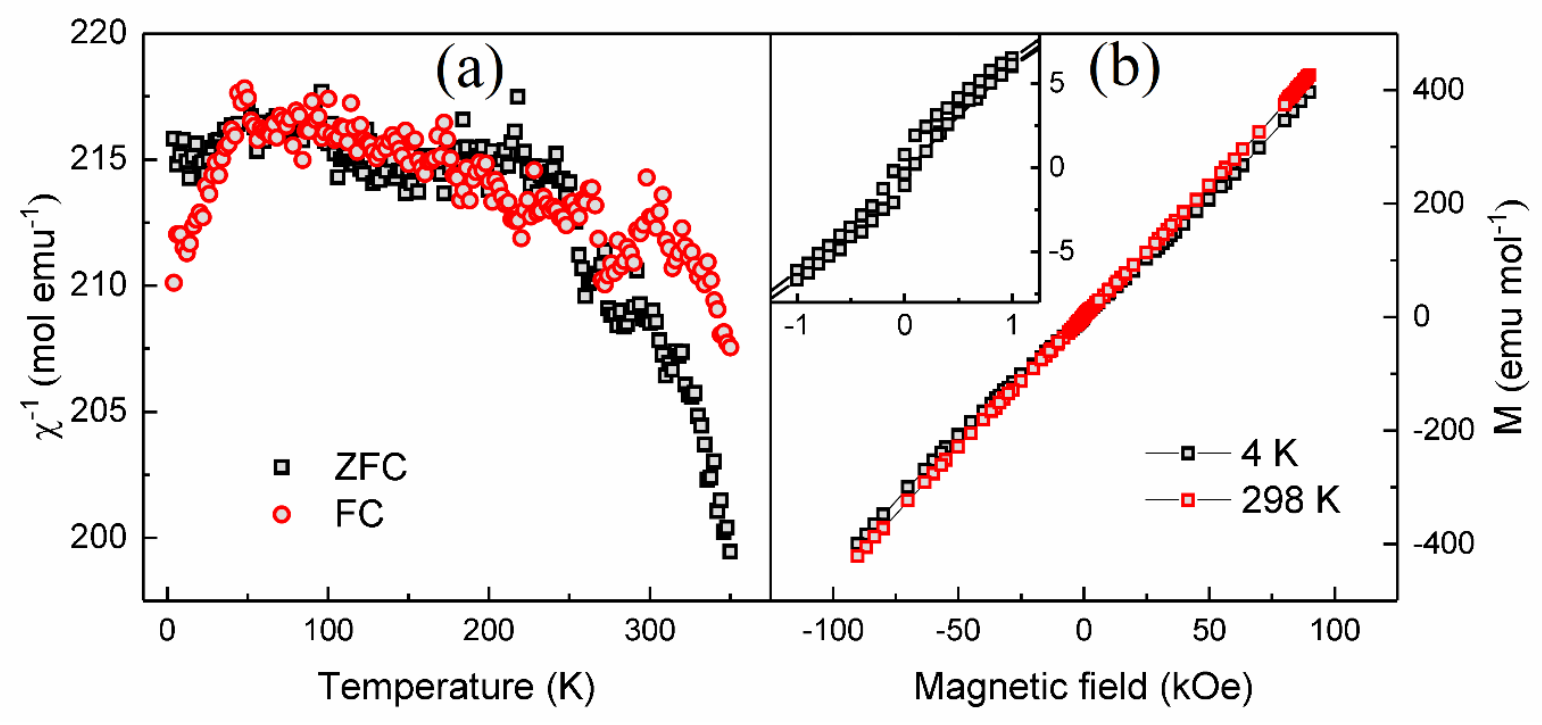

Figure 3: (a) Temperature dependence of the inverse molar magnetic susceptilbility of $\mathrm{LaSr}_{3} \mathrm{Fe}_{3} \mathrm{O}_{9}$ at ZFC and FC conditions and measured in a filed of $10 \mathrm{kOe}$. (b) Field dependence of the molar magnetization of $\mathrm{LaSr}_{3} \mathrm{Fe}_{3} \mathrm{O}_{9}$ at $4 \mathrm{~K}$ (black) and $298 \mathrm{~K}$ (red). The inset shows a small hysteresis.

Oxygen deficiency in $\mathrm{LaSr}_{3} \mathrm{Fe}_{3} \mathrm{O}_{10-x}$ and phase relations between $\mathrm{LaSr}_{3} \mathrm{Fe}_{3} \mathrm{O}_{10-\delta}$ and $\mathrm{LaSr}_{3} \mathrm{Fe}_{3} \mathrm{O}_{9 \pm \varepsilon}$

Thermogravimetry of $\mathrm{LaSr}_{3} \mathrm{Fe}_{3} \mathrm{O}_{9.97}$ upon heating/cooling cycles in $\mathrm{O}_{2}$ and $\mathrm{N}_{2}$ (Figure 4) shows that the oxygen vacancy concentration depends on both temperature and $\mathrm{pO}_{2}$. For example, at $1473 \mathrm{~K}, x=0.76$ in $\mathrm{O}_{2}$, and $x=1.21$ in $\mathrm{N}_{2}$. In addition, upon subsequent cooling in $\mathrm{O}_{2}$ from $1473 \mathrm{~K}$ the sample returns almost to its initial fully oxidized state, whereas on cooling in $\mathrm{N}_{2}$ the sample stabilizes with an oxygen content of $x=0.90$. The modest re-oxidation in $\mathrm{N}_{2}$ during the cooling step is most likely due to oxygen impurities in the $\mathrm{N}_{2}$-gas. Upon heating in $\mathrm{N}_{2}$, $\mathrm{LaSr}_{3} \mathrm{Fe}_{3} \mathrm{O}_{10}$ arrives at the composition of the $\mathrm{LaSr}_{3} \mathrm{Fe}_{3} \mathrm{O}_{9}$ phase, indicating a reversible transformation between the two compounds. Furthermore, the TGA experiments illustrate the system's ability to release and incorporate oxygen in a reversible manner. We observe a weak plateau in the TGA curves at $x=0.2$ on heating in both $\mathrm{N}_{2}$ and $\mathrm{O}_{2}$, and in $\mathrm{N}_{2}$ we note a distinct change in curvature at $x=1.0$. These changes are probably indicative of changes in the oxygen vacancy mechanism. 


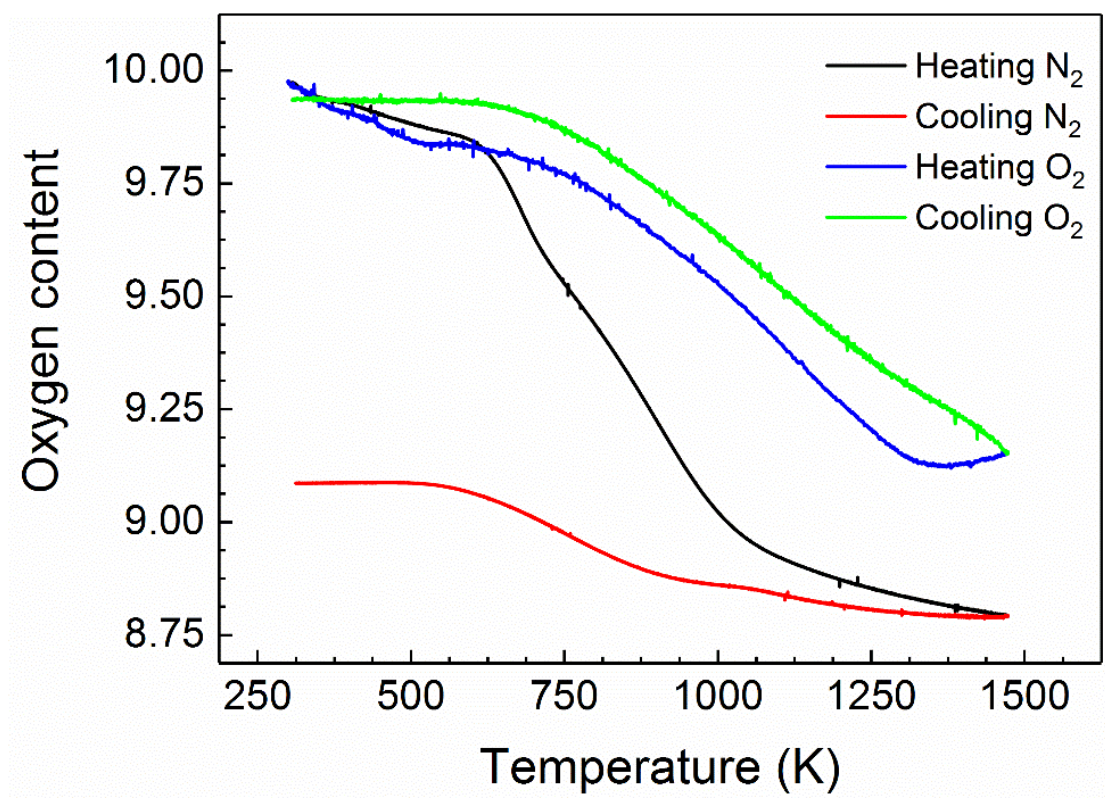

Figure 4: Oxygen content as determined by TGA for $\mathrm{LaSr}_{3} \mathrm{Fe}_{3} \mathrm{O}_{9.97}$ in $\mathrm{N}_{2}$ and $\mathrm{O}_{2}$, heating rate $1 \mathrm{~K}$ min $^{-1}$. The black and blue curves show mass loss during heating in $\mathrm{N}_{2}$ and $\mathrm{O}_{2}$, while the red and green curves show re-oxidation during cooling to room temperature in $\mathrm{N}_{2}$ and $\mathrm{O}_{2}$.

TGA shows that $\mathrm{LaSr}_{3} \mathrm{Fe}_{3} \mathrm{O}_{10-x}$ has a huge span in oxygen content. Correspondingly, $\mathrm{LaSr}_{3} \mathrm{Fe}_{3} \mathrm{O}_{10-\delta}$ and $\mathrm{LaSr}_{3} \mathrm{Fe}_{3} \mathrm{O}_{9 \pm \varepsilon}$ appears as two distinct phases with significant differences in their crystal structures. To correlate the structural state with the overall oxygen content, a series of $\mathrm{LaSr}_{3} \mathrm{Fe}_{3} \mathrm{O}_{10-x}(0<x<1)$ compositions were prepared by controlled $\mathrm{NbO}$ reduction followed by cerimetric titration and structural analysis. The combined structural and oxygen content analysis (Figure 5) show that unit cell volumes of $\mathrm{LaSr}_{3} \mathrm{Fe}_{3} \mathrm{O}_{10-\delta}$ and $\mathrm{LaSr}_{3} \mathrm{Fe}_{3} \mathrm{O}_{9 \pm \varepsilon}$ vary significantly with oxygen deficiency concentration and reveal that $\mathrm{LaSr}_{3} \mathrm{Fe}_{3} \mathrm{O}_{10-\delta}$ retains its structure to $\delta=0.51\left(\mathrm{LaSr}_{3} \mathrm{Fe}_{3} \mathrm{O}_{9.49}\right)$. For the interval $0.51<x<0.85$, the two phases $\mathrm{LaSr}_{3} \mathrm{Fe}_{3} \mathrm{O}_{10-\delta}$ and $\mathrm{LaSr}_{3} \mathrm{Fe}_{3} \mathrm{O}_{9 \pm \varepsilon}$ co-exists, whereas for $x>0.85$ non-stoichiometric $\mathrm{LaSr}_{3} \mathrm{Fe}_{3} \mathrm{O}_{9 \pm \varepsilon}$ is the stable configuration. $\mathrm{LaSr}_{3} \mathrm{Fe}_{3} \mathrm{O}_{9 \pm \varepsilon}$ is associated with a small, yet significant solid solution range of oxygen; $\varepsilon<0.15$. Furthermore, TGA (Figure 4) suggest that the $\mathrm{LaSr}_{3} \mathrm{Fe}_{3} \mathrm{O}_{9 \pm \varepsilon}$ phase also exists with oxygen vacancies up to $x=1.21$ (i.e. $\mathrm{LaSr}_{3} \mathrm{Fe}_{3} \mathrm{O}_{8.79}$ ). The latter finding is in good agreement with observations for the isostructural $\mathrm{NdSr}_{3} \mathrm{Fe}_{3} \mathrm{O}_{9}$ compound. $[8,9]$ 


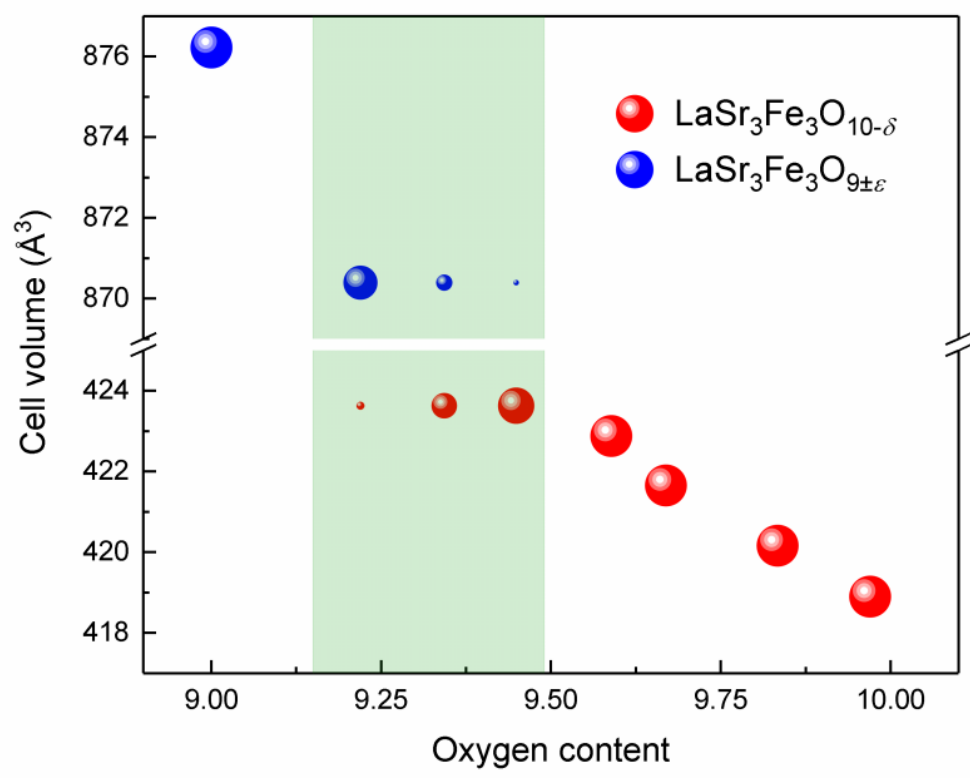

Figure 5: Phase relations and unit cell volumes of $\mathrm{LaSr}_{3} \mathrm{Fe}_{3} \mathrm{O}_{10-\delta}$ (red spheres) and $\mathrm{LaSr}_{3} \mathrm{Fe}_{3} \mathrm{O}_{9 \pm \varepsilon}$ (blue spheres) for $\mathrm{LaSr}_{3} \mathrm{Fe}_{3} \mathrm{O}_{10-x}$ samples prepared by means of controlled oxygen reduction. The shaded area illustrates the two-phase region $(0.51<x<0.85)$. The size of symbols illustrates the mole fraction of the individual phases in the two-phase region.

The TGA study shows that oxidation and reduction are fast reactions (Figure 4). However, the structural analysis at $295 \mathrm{~K}$ documents that $\mathrm{LaSr}_{3} \mathrm{Fe}_{3} \mathrm{O}_{9 \pm \varepsilon}$ and $\mathrm{LaSr}_{3} \mathrm{Fe}_{3} \mathrm{O}_{10-\delta}$ are two distinct phases, crystallizing in orthorhombic and tetragonal symmetries, respectively. On that basis, we expect a discontinuity, or a two-phase region, connecting the reduced and oxidized variants. This is confirmed by the unit cell volumes of the tailor-made oxygen stoichiometry samples (Figure 5). In order to clarify the transition between the two phases, an in-situ SR-XRD experiment was carried out. A sample with initial nominal composition $\mathrm{LaSr}_{3} \mathrm{Fe}_{3} \mathrm{O}_{9.22}$ (i.e., at the verge to two-phase region with $\mathrm{LaSr}_{3} \mathrm{Fe}_{3} \mathrm{O}_{9 \pm \varepsilon}$ as the dominant phase) was heated to $663 \mathrm{~K}$ in a closed capillary. Regular thermal expansion was observed, and at $663 \mathrm{~K}$ the capillary was opened to the air while the progressing oxidation of the sample was monitored.

By inspection of the diffraction patterns (Figure 6), it is evident that the sample is composed of $\mathrm{LaSr}_{3} \mathrm{Fe}_{3} \mathrm{O}_{9 \pm \varepsilon}$ and $\mathrm{LaSr}_{3} \mathrm{Fe}_{3} \mathrm{O}_{10-\delta}$ at $663 \mathrm{~K}$ and that no other high temperature phase is formed. No continuous conversion of $\mathrm{LaSr}_{3} \mathrm{Fe}_{3} \mathrm{O}_{9 \pm \varepsilon}$ into $\mathrm{LaSr}_{3} \mathrm{Fe}_{3} \mathrm{O}_{10-\delta}$ is observed, i.e. they exist as a two-phase mixture while the phase fraction changes during the progressing oxidation. Further, in the early stage of the oxidation process, we clearly observe that the (117) reflection of $\mathrm{LaSr}_{3} \mathrm{Fe}_{3} \mathrm{O}_{10-\delta}$ moves to higher $Q$, and thus a smaller unit cell volume (Figure 6). This indicates 
oxidation of $\mathrm{LaSr}_{3} \mathrm{Fe}_{3} \mathrm{O}_{10-}$, consistent with the ability to incorporate oxygen in vacant sites. The process was quantified through surface Rietveld refinements, and Figure S3 shows the evolution of the unit cell volume of $\mathrm{LaSr}_{3} \mathrm{Fe}_{3} \mathrm{O}_{10-\delta}$ and phase fractions throughout the oxidation. Initially, the unit cell volume decreases rapidly, followed by a more moderate contraction. This shows that $\mathrm{LaSr}_{3} \mathrm{Fe}_{3} \mathrm{O}_{10-\delta}$ is continuously incorporating oxygen throughout the entire experiment. The initial rapid decrease in the cell volume is attributed to the system's response to the change in partial $\mathrm{pO}_{2}$ over the sample when the capillary was cut open.
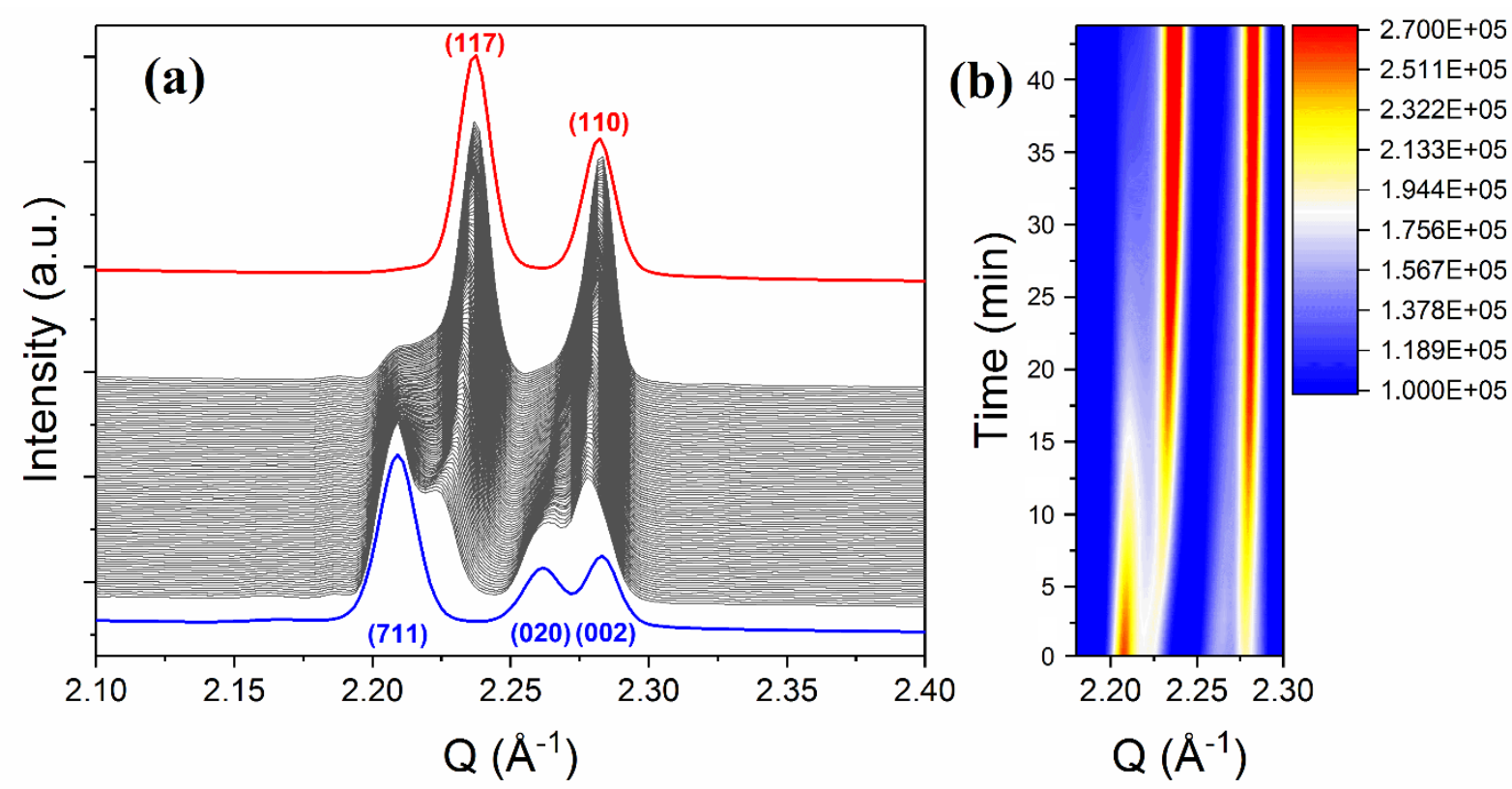

Figure 6: (a) Stacked in situ SR-XRD patterns for oxidation of $\mathrm{LaSr}_{3} \mathrm{Fe}_{3} \mathrm{O}_{9.22}$ in an open capillary at $663 \mathrm{~K}$ versus time. The blue (first) and red (last) patterns are the calculated intensities associated with orthorhombic $\mathrm{LaSr}_{3} \mathrm{Fe}_{3} \mathrm{O}_{9 \pm \varepsilon}$ and tetragonal $\mathrm{LaSr}_{3} \mathrm{Fe}_{3} \mathrm{O}_{10-\delta}$ in the first and the last diffraction pattern, respectively. Miller indices are given for the respective reflections. Phase fractions from Rietveld refinements are shown in Figure S3. (b) Contour plot illustrating the evolution of the diffraction pattern of the $\mathrm{LaSr}_{3} \mathrm{Fe}_{3} \mathrm{O}_{9 \pm \varepsilon}$ and $\mathrm{LaSr}_{3} \mathrm{Fe}_{3} \mathrm{O}_{10-\delta}$ versus time in same $Q$ region as (a). Note that the sample is in a two-phase region though the entire experiment.

\section{Vacancy formation and vacancy ordering in $\mathrm{LaSr}_{3} \mathrm{Fe}_{3} \mathrm{O}_{10-\delta}$ and $\mathrm{LaSr}_{3} \mathrm{Fe}_{3} \mathrm{O}_{9 \pm \varepsilon}$}

In general, iron cations are well known to coordinate as octahedra (6), tetragonal pyramids (5) or tetrahedra (4), and in some rare cases also in square planar (4) coordination $\left(\mathrm{SrFeO}_{2}\right)$.[19] Concerning $\mathrm{LaSr}_{3} \mathrm{Fe}_{3} \mathrm{O}_{10}$, Tsipis et al. suggested that oxygen vacancies are located to the central layer of the perovskite slab giving rise to tetrahedrally coordinated iron.[7] In Figure 5, we 
observe that the unit cell volumes of $\mathrm{LaSr}_{3} \mathrm{Fe}_{3} \mathrm{O}_{10-\delta}$ and $\mathrm{LaSr}_{3} \mathrm{Fe}_{3} \mathrm{O}_{9 \pm \varepsilon}$ vary significantly with oxygen deficiency concentration. With basis in unit cell volume considerations due to oxygen deficiency in $\mathrm{SrFeO}_{3-x}\left(\mathrm{SrFeO}_{3}, \mathrm{Sr}_{8} \mathrm{Fe}_{8} \mathrm{O}_{23}, \mathrm{Sr}_{4} \mathrm{Fe}_{4} \mathrm{O}_{11}\right)$ and $\mathrm{LaCoO}_{3-x}\left(\mathrm{LaCoO}_{3}, \mathrm{La}_{3} \mathrm{Co}_{3} \mathrm{O}_{8}\right.$, $\mathrm{La}_{2} \mathrm{Co}_{2} \mathrm{O}_{5}$ ), one may identify the likely local vacancy ordering scheme in $\mathrm{LaSr}_{3} \mathrm{Fe}_{3} \mathrm{O}_{10-\delta}$ and $\mathrm{LaSr}_{3} \mathrm{Fe}_{3} \mathrm{O}_{9 \pm \varepsilon} . \mathrm{SrFeO}_{3-x}$ and $\mathrm{LaCoO}_{3-x}$ represent two different vacancy situations; 5-coordinated tetragonal pyramids and 4-coordinated tetrahedra, respectively.[20-22] Based on literature data for these two $\mathrm{ABO}_{3-x}$ systems, the volume expansion as a function of oxidation state of the $\mathrm{B}$ cations in $\mathrm{SrFeO}_{3-x}$ and $\mathrm{LaCoO}_{3-x}$ are plotted along with corresponding data for $\mathrm{LaSr}_{3} \mathrm{Fe}_{3} \mathrm{O}_{10-\delta}$ and $\mathrm{LaSr}_{3} \mathrm{Fe}_{3} \mathrm{O}_{9 \pm \varepsilon}$ in Figure S4. The volume - composition slopes are reported in Table 4.

Table 4: Volume expansion slopes derived from linear regression of the volume versus B-cation oxidation state. ${ }^{a}$ Derived value for the two data points with largest unit cell volume of $\mathrm{LaSr}_{3} \mathrm{Fe}_{3} \mathrm{O}_{10-\delta}(\delta=0.03$ and 0.17$)$ in Figure 5. ${ }^{\mathrm{b}}$ Derived value for the two data points with smallest unit cell volume of $\mathrm{LaSr}_{3} \mathrm{Fe}_{3} \mathrm{O}_{10-\delta}(\delta=0.33$ and 0.41$)$ in Figure 5 .

$\begin{array}{lllll}\text { System } & \mathrm{SrFeO}_{3-x} & \mathrm{LaCoO}_{3-x} & \mathrm{LaSr}_{3} \mathrm{Fe}_{3} \mathrm{O}_{10-\delta} & \mathrm{LaSr}_{3} \mathrm{Fe}_{3} \mathrm{O}_{9 \pm \varepsilon} \\ \text { Vacancy type } & \text { Tetragonal } & \text { Tetrahedra }[21, & \text { Unknown } & \text { Tetrahedra } \\ & \text { pyramids[20] } & 22] & & \\ \text { Slope } & -1.42 & -5.33 & -3.01 & -5.76 \\ & & & -2.32^{\mathrm{a}} & \\ & & & -3.80^{\mathrm{b}} & \end{array}$

From Table 4 (and Figure S4) we note that the local vacancy ordering influences the unit cell volume expansion significantly as seen by comparing data for $\mathrm{SrFeO}_{3-x}$ and $\mathrm{LaCoO}_{3-x}$. Notably, for both $\mathrm{LaCoO}_{3-x}$ and $\mathrm{LaSr}_{3} \mathrm{Fe}_{3} \mathrm{O}_{9 \pm \varepsilon}$ the $\mathrm{B}$ site cations partly take tetrahedral coordination and the volume slopes are similar (-5.33 and -5.76). The similar slopes are a signature of both these systems having tetrahedra as their local ordering scheme of vacancies. When it comes to $\mathrm{LaSr}_{3} \mathrm{Fe}_{3} \mathrm{O}_{10-\delta}$, the situation is less clear with an average volume slope of -3.01, i.e. an intermediate situation relative to local vacancy ordering by tetrahedra (-5.33) and by tetragonal pyramids (-1.42). This may indicate that both these local configurations exist in oxygen deficient $\mathrm{LaSr}_{3} \mathrm{Fe}_{3} \mathrm{O}_{10-\delta}$.

By considering Figure 5 in more detail, a small change in the unit cell volume slope is seen around $x=0.25, c f$. also Table 4 and Figure S4. Although the change is small, the TGA data in Figure 4 shows a clear feature at approximately the same oxygen content. Note, the kink in 
TGA is at higher temperatures, whereas Figure 5 represents a quenched situation at $\mathrm{NbO}$ reducing conditions. These observations suggest a composition mediated change in the local vacancy ordering mechanism. The two observed volume slopes of $\mathrm{LaSr}_{3} \mathrm{Fe}_{3} \mathrm{O}_{10-\delta}$ are -2.32 for $\delta<0.25$ and -3.80 for $\delta>0.25$. Although neither of these clearly support one ordering scheme above the other, we suggest that initial formation of tetragonal pyramids is replaced by tetrahedra at high vacancy concentrations. To fully reveal the vacancy-ordering situation, we suggest revisiting the system by computational modelling and to perform pair distribution function (PDF) analysis of ND data as the next steps.

\section{Summary}

This study is the first report on the crystal- and magnetic structure of $\mathrm{LaSr}_{3} \mathrm{Fe}_{3} \mathrm{O}_{9}$. The title compound is isostructural to $\mathrm{NdSr}_{3} \mathrm{Fe}_{3} \mathrm{O}_{9}$. By means of magnetization and $\mathrm{ND}$ we conclude that $\mathrm{LaSr}_{3} \mathrm{Fe}_{3} \mathrm{O}_{9}$ is a G-type antiferromagnet, described in the magnetic space group $P_{C} b c m$, with a Néel temperature above $350 \mathrm{~K}$ possible similar to that of $\mathrm{NdSr}_{3} \mathrm{FeO}_{9}$ and $\mathrm{LaSr}_{2} \mathrm{Fe}_{3} \mathrm{O}_{8+y}$. $[8,10]$. TGA shows that the $\mathrm{LaSr}_{3} \mathrm{Fe}_{3} \mathrm{O}_{10-x}$ phases can reversibly accommodate and release oxygen in the range $0<x<1.21$. However, in this wide oxygen range, two distinct RP3 like phases are occurring; $\mathrm{LaSr}_{3} \mathrm{Fe}_{3} \mathrm{O}_{10-\delta}$ and $\mathrm{LaSr}_{3} \mathrm{Fe}_{3} \mathrm{O}_{9 \pm \varepsilon}$, separated by a two-phase region. By combining information from TGA and structural considerations, we propose that oxygen deficient $\mathrm{LaSr}_{3} \mathrm{Fe}_{3} \mathrm{O}_{10-\delta}$ initially form tetragonal pyramids as local oxygen coordination, which are replaced by tetrahedra at higher vacancy concentrations. We suggest this issue is carefully addressed in future work by computational modelling and PDF analysis of ND.

\section{Acknowledgment}

This work is part of activities in the FOXHOUND and NOFCO projects. FOXHOUND is funded by The Faculty of Mathematics and Natural Sciences, University of Oslo via the Strategic Research Initiative program. NOFCO is supported by the Research Council of Norway (Grant no. 221905). The authors acknowledge the use of the Norwegian Center for Xray Diffraction, Scattering and Imaging (RECX) and gratefully acknowledged the staff at the Swiss-Norwegian Beam Lines (SNBL), ESRF, France, for technical support.

\section{Author Information}

*E-mail: a.o.sjastad@kjemi.uio.no 


\section{References:}

[1] D.W. Murphy, S. Sunshine, R.B. van Dover, R.J. Cava, B. Batlogg, S.M. Zahurak, L.F. Schneemeyer, New superconducting cuprate perovskites, Phys. Rev. Lett. 58(18) (1987) 18881890.

[2] H. Liu, X. Yang, A brief review on perovskite multiferroics, Ferroelectrics 507(1) (2017) 69-85.

[3] F. Polo-Garzon, Z. Wu, Acid-base catalysis over perovskites: a review, J. Mater. Chem. A 6(7) (2018) 2877-2894.

[4] B. Raveau, A. Maignan, C. Martin, M. Hervieu, Colossal Magnetoresistance Manganite Perovskites: Relations between Crystal Chemistry and Properties, Chem. Mater. 10(10) (1998) 2641-2652.

[5] D. Pergolesi, E. Fabbri, A. D’Epifanio, E. Di Bartolomeo, A. Tebano, S. Sanna, S. Licoccia, G. Balestrino, E. Traversa, High proton conduction in grain-boundary-free yttrium-doped barium zirconate films grown by pulsed laser deposition, Nat. Mater. 9 (2010) 846.

[6] J.Y. Lee, J.S. Swinnea, H. Steinfink, W.M. Reiff, S. Pei, J.D. Jorgensen, The Crystal Chemistry and Physical Properties of the Triple Layer Perovskite Intergrowths $\mathrm{LaSr}_{3} \mathrm{Fe}_{3} \mathrm{O}_{10-\delta}$ and $\mathrm{LaSr}_{3}\left(\mathrm{Fe}_{3-\mathrm{x}} \mathrm{Al}_{\mathrm{x}}\right) \mathrm{O}_{10-\delta}$, J. Solid State Chem. 103(1) (1993) 1-15.

[7] E.V. Tsipis, E.N. Naumovich, M.V. Patrakeev, P.V. Anikina, J.C. Waerenborgh, V.V. Kharton, Defect Interactions in $\mathrm{Sr}_{3} \mathrm{La}(\mathrm{Fe}, \mathrm{Al})_{3} \mathrm{O}_{10-\delta}$ by Computer Simulations and Mössbauer Spectroscopy, Chem. Mater. 21(21) (2009) 5072-5078.

[8] N. Barrier, D. Pelloquin, N. Nguyen, M. Giot, F. Bourée, B. Raveau, Ferrite $\mathrm{Sr}_{3} \mathrm{NdFe}_{3} \mathrm{O}_{9}$ : An Original Intergrowth between the Brownmillerite and $\mathrm{K}_{2} \mathrm{NiF}_{4}$-type Structures, Chem. Mater. 17(26) (2005) 6619-6623.

[9] D. Pelloquin, J. Hadermann, M. Giot, V. Caignaert, C. Michel, M. Hervieu, B. Raveau, Novel, Oxygen-Deficient $\mathrm{n}=3 \mathrm{RP}-\mathrm{Member} \mathrm{Sr}_{3} \mathrm{NdFe}_{3} \mathrm{O}_{9-\delta}$ and Its Topotactic Derivatives, Chem. Mater. 16(9) (2004) 1715-1724.

[10] P.D. Battle, T.C. Gibb, S. Nixon, A study of the ordering of oxygen vacancies in the nonstoichiometric perovskite $\mathrm{Sr}_{2} \mathrm{LaFe}_{3} \mathrm{O}_{8+\mathrm{y}}$ by Mössbauer spectroscopy and a comparison with $\mathrm{SrFeO}_{3-y}$, J. Solid State Chem. 79(1) (1989) 75-85.

[11] P.D. Battle, T.C. Gibb, P. Lightfoot, The crystal and magnetic structures of $\mathrm{Sr}_{2} \mathrm{LaFe}_{3} \mathrm{O}_{8}$, J. Solid State Chem. 84(2) (1990) 237-244.

[12] V. Øygarden, H. Fjellvåg, M.H. Sørby, A.O. Sjåstad, Crystal Structure of $\mathrm{LaSr}_{3} \mathrm{Fe}_{3} \mathrm{O}_{8}(\mathrm{OH})_{2} \cdot \mathrm{xH}_{2} \mathrm{O}$, Inorg. Chem. 55(15) (2016) 7630-7636.

[13] T. Takeguchi, T. Yamanaka, H. Takahashi, H. Watanabe, T. Kuroki, H. Nakanishi, Y. Orikasa, Y. Uchimoto, H. Takano, N. Ohguri, M. Matsuda, T. Murota, K. Uosaki, W. Ueda, Layered Perovskite Oxide: A Reversible Air Electrode for Oxygen Evolution/Reduction in Rechargeable Metal-Air Batteries, J. Am. Chem. Soc. 135(30) (2013) 11125-11130. 
[14] B.C. Hauback, H. Fjellvåg, O. Steinsvoll, K. Johansson, O.T. Buset, J. Jørgensen, The high resolution Powder Neutron Diffractometer PUS at the JEEP II reactor at Kjeller in Norway, J. Neutron Res. 8(3) (2000) 215-232.

[15] Bruker-AXS, TOPAS V5: General profile and structure analysis software for powder diffraction data, Bruker AXS, Karlsruhe, Germany., 2013.

[16] A. Coelho, TOPAS and TOPAS-Academic: an optimization program integrating computer algebra and crystallographic objects written in C++, J. Appl. Crystallogr. 51(1) (2018) 210-218.

[17] H.T. Stokes, D.M. Hatch, B.J. Campbell, D.E. Tanner, ISODISPLACE: a web-based tool for exploring structural distortions, J. Appl. Crystallogr. 39(4) (2006) 607-614.

[18] I.D. Brown, D. Altermatt, Bond-valence parameters obtained from a systematic analysis of the Inorganic Crystal Structure Database, Acta Crystallogr., Sect. B 41(4) (1985) 244-247.

[19] Y. Tsujimoto, C. Tassel, N. Hayashi, T. Watanabe, H. Kageyama, K. Yoshimura, M. Takano, M. Ceretti, C. Ritter, W. Paulus, Infinite-layer iron oxide with a square-planar coordination, Nature 450 (2007) 1062.

[20] J.P. Hodges, S. Short, J.D. Jorgensen, X. Xiong, B. Dabrowski, S.M. Mini, C.W. Kimball, Evolution of Oxygen-Vacancy Ordered Crystal Structures in the Perovskite Series $\mathrm{Sr}_{n} \mathrm{Fe}_{\mathrm{n}} \mathrm{O}_{3 \mathrm{n}-1}$ $(\mathrm{n}=2,4,8$, and $\infty)$, and the Relationship to Electronic and Magnetic Properties, J. Solid State Chem. 151(2) (2000) 190-209.

[21] O.H. Hansteen, H. Fjellvåg, B.C. Hauback, Crystal Structure and Magnetic Properties of $\mathrm{La}_{2} \mathrm{Co}_{2} \mathrm{O}_{5}$, J. Solid State Chem. 141(2) (1998) 411-417.

[22] O. H. Hansteen, H. Fjellvåg, B. C. Hauback, Crystal structure, thermal and magnetic properties of $\mathrm{La}_{3} \mathrm{Co}_{3} \mathrm{O}_{8}$. Phase relations for $\mathrm{LaCoO}_{3-\delta}(0.00 \leq \delta \leq 0.50)$ at $673 \mathrm{~K}$, J. Mater. Chem. 8(9) (1998) 2081-2088. 